\title{
The Treatment of Chronic Hepatitis C Virus Infection IN HIV CO-INFECTION
}

\author{
Martin Vogel, Jürgen K. Rockstroh \\ Department of Internal Medicine I, Bonn University, Bonn, Germany
}

\begin{abstract}
Chronic HCV co-infection is present in up to one third of $\mathrm{HIV}$-positive patients in Europe. In recent years, apart from the traditional transmission route of intravenous drug abuse, outbreaks of sexually transmitted acute HCV infections, mainly among HIV-positive men who have sex with men, have contributed to the overall disease burden.

Because the natural course of $\mathrm{HCV}$ infection is substantially accelerated in HIV-co-infection, endstage liver disease has become the most frequent cause of non-AIDS related death in this population. Therefore every $\mathrm{HIV} / \mathrm{HCV}$ co-infected patient should be evaluated for possible anti-HCV therapy with the goal of reaching a sustained virological response and thus cure of hepatitis $\mathrm{C}$ infection. The standard of care for the treatment of chronic HCV infection in HIV-infected remains a pegylated interferon in combination with weight-adapted ribavirin.
\end{abstract}

HAART should not be withheld from HCV co-infected patients due to concerns of drug related hepatotoxicity and in patients with reduced CD4-cell counts HAART should be started first. Under pegylated interferon and ribavirin combination therapy drug to drug interactions and cumulated toxicity between nucleoside analogues and anti-HCV therapy may be observed and concomitant didanosine use is contraindicated and zidovudine and stavudine should be avoided if possible.

The development of new drugs for the treatment of chronic hepatitis $C$ represents a promising perspective also for HIV positive patients. However, these substances will probably reach clinical routine for HIV patients later than HCV monoinfected patients. Therefore at present waiting for new drugs is not an alternative to a modern pegylated interferon/ribavirin therapy.

\section{INTRODUCTION}

With the availability of highly active antiretroviral therapy (HAART) in 1996 [1], a dramatic decline of AIDS-associated mortality has been observed. Accordingly, in the health management of the aging HIVpositive patient, co-morbidities such as chronic liver and cardiovascular disease are increasingly demanding clinical attention. In hepatitis $\mathrm{C}$ virus (HCV) co-infected patients liver-related disease has emerged as a leading cause of morbidity and mortality [2]. Owing to similar routes of transmission, HCV and HIV are often found in the same host. In Europe, up to one third of all HIV patients are co-infected with HCV [3].

The progression of chronic HCV infection to liver cirrhosis with subsequent risk for liver decompensation and hepatocellular carcinoma is substantially accelerated in $\mathrm{HIV} / \mathrm{HCV}$ co-infected compared to HCV mono-infected individuals [4, 5]. The sequelae of chronic hepatitis $\mathrm{C}$ infection however may be stopped by successful treatment with pegylated interferon and ribavirin combination therapy so that every $\mathrm{HIV} / \mathrm{HCV}$ coinfected patient should be evaluated for possible HCV treatment [6].

In the following review we want to summarize the current epidemiological and treatment data and discuss these with particular regard to the recently updated guidelines of the European AIDS Society in 2009 for the treatment of chronic hepatitis $C$ infection in HIV coinfected patients.

\section{EPIDEMIOLOGY}

Little is known on the epidemiology of HCV infection in the setting of HIV co-infection. Recently the EuroSIDA cohort, the largest prospective cohort of HIV-positive patients in Europe, was analyzed to this regard [3]. Within EuroSIDA, of 14310 patients who were tested at enrollment 3375 (24\%) were anti-HCV positive at baseline. There are, however, marked differences in the prevalence of positive anti-HCV antibodies throughout Europe, reflecting differences in the proportion of HIV infections transmitted via intravenous drug abuse, still the most important risk factor for the acquisition of hepatitis $\mathrm{C}$ in the European HIV-positive population [7]. Whereas countries with a traditionally high burden of HIV-positive intravenous drug abusers have high rates of $\mathrm{HCV}$ co-infection with $47 \%$ and $41 \%$ of patients in Eastern and Southern Europe positive for anti-HCV antibodies, respectively, countries with MSM being the prevailing mode of HIV-transmission have lower rates of chronic $\mathrm{HCV}$ infection with a prevalence of anti-HCV antibody of $20 \%$ and $23 \%$ of patients in Central and Northern Europe, respectively [8]. These rates are clearly higher compared to the HIV-negative population, where rates of $\mathrm{HCV}$-prevalence have been reported to be between $2.5-10 \%$ in Romania and Ukraine and $1-2.5 \%$ in the remaining countries of the WHO region of Europe [9]. With the implementa- 
tion of syringe exchange programs, opioid substitution and social prevention efforts a further expansion of intravenous drug abuse related HCV infections have been successfully contained in Western Europe. For instance, in Spain a significant decrease in the overall prevalence of HCV co-infection among Spanish patients newly diagnosed with HIV has been observed, decreasing from $24 \%$ in 2000 - 2002 down to $10 \%$ in the period $2006-2008$ [10]. Unfortunately in Eastern Europe, where harm reduction strategies have not yet been installed on a large scale [11], the HIV and HCV epidemic among intravenous drug abusers is at risk to continue unbroken in some countries [12].

In Western Europe, and recently the USA and Australia, new outbreaks of sexually transmitted HCV infections have been reported among men who have sex with men [7, 13-22], which continue to increase the disease burden of HCV co-infection within the HIV community and worries have been raised that this epidemic may leap over and spread within the HIV-negative MSM community as a "new" sexually transmitted disease. These concerns may be overstated as in a recent epidemiological survey among genito-uterine medicine (GUM) and HIV clinics in London and Brighton area on acute HCV infections among MSM, of 395 acute HCV infections between 2002 and 2006, 389 had occurred in HIV-positive patients [15]. Similarly Urbanus and colleagues investigated into the prevalence of $\mathrm{HCV}$ infection among MSM attending the sexually transmitted disease clinic in Amsterdam [20]. They found a significantly higher HCV prevalence among those co-infected with HIV (28 / 157, $18 \%$ ) and history of intravenous drug use, fisting, and the use of gamma hydroxy butyrate (GHB) were all significantly associated with an increased risk for $\mathrm{HCV}$ infection. Only two of $532 \mathrm{HIV}$-negative MSM were found to be HCV positive, and one of these reported previous intravenous drug and these observations would be in line with past longitudinal studies of HCV serodiscordant heterosexual partnerships, where the life-time risk for sexual transmission of HCV was estimated to be $<1 \%[23,24]$. Nevertheless in the MSM population due to different sexual practices the risk for sexually acquired HCV infection may be higher than among heterosexual couples and increases of acute $\mathrm{HCV}$ infections among HIV-negative MSM have been reported. Continued prevention efforts on sexual transmission of HCV within the MSM community, regardless of HIV serostatus, therefore only appear prudent [25].

\section{Natural Course of Hepatitis C IN HIV CO-INFECTION}

While hepatitis $\mathrm{C}$ infection does not have a relevant influence on the course of HIV infection, HIV infection accelerates the natural course of hepatitis $C$ infection. HIV/HCV coinfected patients show a rapid progression of liver fibrosis in contrast to HCV monoinfected patients $[4,26]$. Of $174 \mathrm{HIV} / \mathrm{HCV}$ coinfected patients which showed at the time-point of the first liver biopsy no or only minimal fibrosis, one third progressed more than two fibrosis stages on a scale from 0-6 (ISHAK score) [5]. Indeed in the HAART era end- stage liver-disease has become the main cause of morbidity and mortality in HIV/HCV coinfected patients [2]. Thus it is crucial for the future health of each $\mathrm{HIV} / \mathrm{HCV}$ coinfected patient to assess risks and benefits of a pegylated interferon ribavirin combination therapy. A successful treatment of chronic hepatitis C has not only proven to stop the progression of liver fibrosis but to result in a survival benefit for patients $[6,27]$.

\section{Pegylated Interferon AND RibaViRIN IN THE SETTING OF HAART}

Treatment of hepatitis $C$ infection with pegylated interferon and ribavirin may be better tolerated if started without concurrent HAART [28]. Therefore, if $\mathrm{HIV}$ infection is not advanced and there is no indication for HAART in the presence of high CD4-counts $(>500 / \mu \mathrm{l})$, a treatment of chronic hepatitis $\mathrm{C}$ infection should be started prior to initiation of HAART [29]. In a recent analysis of one of the largest studies on the treatment of $\mathrm{HIV}$-infected with HCV infection, the APRICOT study, a relative CD4-cell count above $25 \%$ was associated with better treatment outcome than lower CD4-cell counts and initiation of HAART is strongly recommended prior to HCV therapy if the CD4-cell count is $<350 / \mu \mathrm{l}$ [30]. Anti-HCV therapy in HIV co-infected individuals has been shown to be complicated by additive drug toxicities of pegylated interferon and ribavirin with the antiretroviral nucleosides didanosine [31, 32], zidovudine [33-35] and stavudine [36]. More recently, competitive phosphorylation between the guanosine nucleoside analogues abacavir and ribavirin has been hypothesized to further compromise anti-HCV treatment efficacy [37-39], though this effect was no longer observed in analysis restricted to patients who had received weight based doses of ribavirin [39, 40]. If feasible from the perspective of resistance and antiretroviral activity of the ART regimen, a tenofovir-based nucleoside backbone or even NRTI-free HAART should be chosen for the duration of anti-HCV therapy. In countries where tenofovir is not yet licensed or contraindications for the use of tenofovir exist, an abacavir based NRTI backbone may be considered if adequate ribavirin dosages are chosen. Therapeutic drug monitoring of ribavirin would also be an alternative to ensure that adequate ribavirin levels of $>3.2 \mu \mathrm{g} / \mathrm{ml}$ are being achieved [39].

\section{Diagnostic Procedures For HCV IN HIV CO-INFECTION}

Due to the increased prevalence of $\mathrm{HCV}$ co-infection every HIV-positive patient should be evaluated for anti-HCV antibodies at the time of first presentation and on an annual basis thereafter (Table 1). It is important to remember that anti-HCV seroconversion after acute HCV infection may be significantly delayed in HIV-positive patients and 5\% of patients had not developed anti-HCV antibodies despite ongoing viral replication for one year in a recent study [41]. Moreover, anti-HCV antibodies may be lost during followup, in particular with advanced degrees of immunode- 
Table 1. Diagnostic procedures for hepatitis C in HIV co-infection.

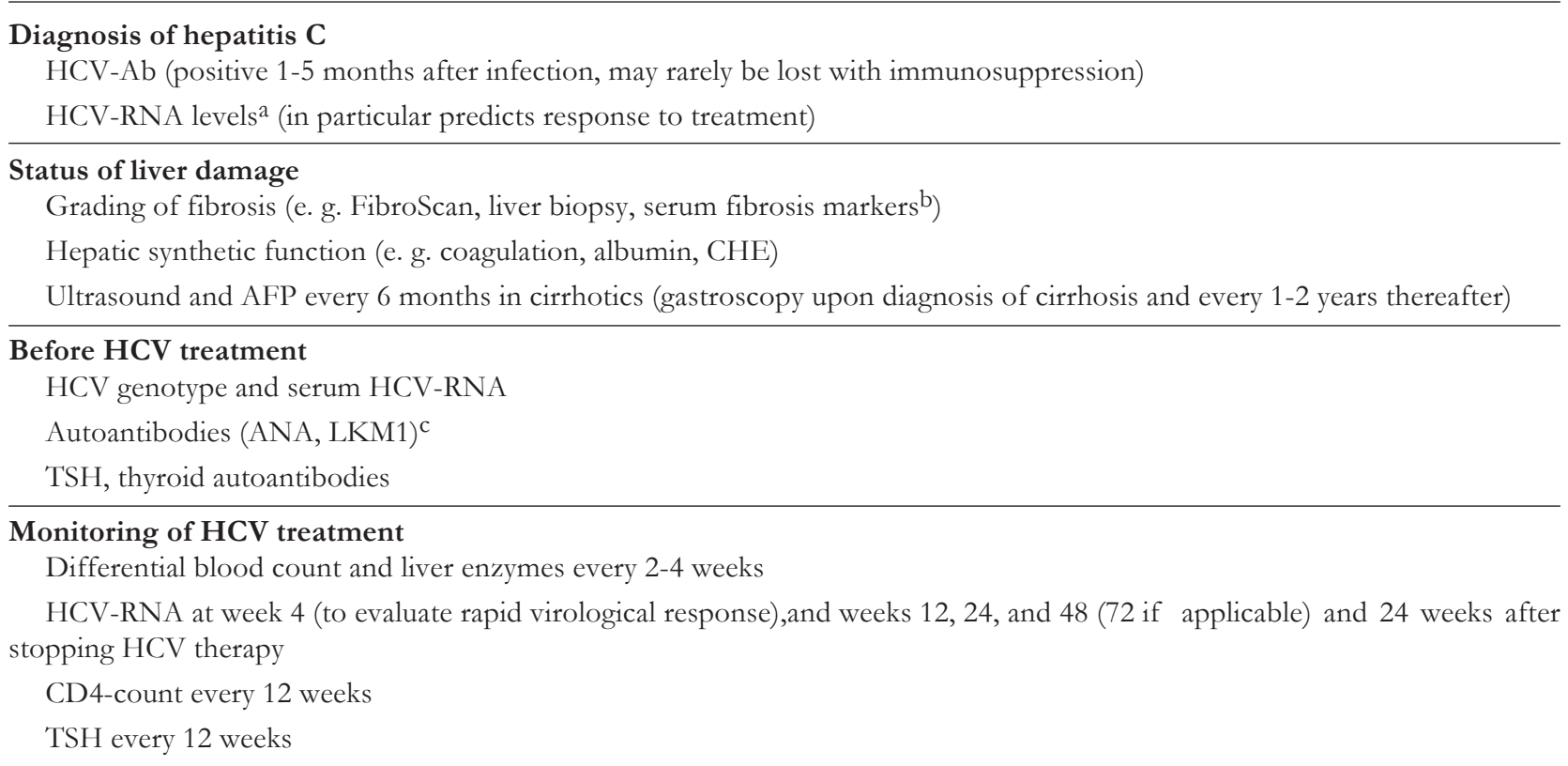

Recommendations according to the current EACS guidelines on the treatment of HIV/HCV co-infection.

a) Low viral load defined as less than $400,000-500,000 \mathrm{IU} / \mathrm{ml}$ when using PegINF+RBV. There is no standard conversion formula for converting the amount of HCV-RNA reported in copies $/ \mathrm{ml}$ to the amount reported in $\mathrm{IU} / \mathrm{ml}$. The conversion factor ranges from about one to five HCV-RNA copies per IU/ml.

b) Serum fibrosis markers include APRI, FIB-4, Hyaluronic acid, Fibrometer, Fibrotest, Forns, Hepascore and other indices; recently more complex tests such as Fibrometer, Fibrotest and Hepascore have shown to more accurately predict liver fibrosis than simple biochemical tests such as APRI, FIB-4 or Forns.

c) Patients with positive anti LKM or ANA with homogeneous pattern should be evaluated for concurrent autoimmune hepatitis especially in the presence of ALT elevation during treatment.

ficiency [42]. Therefore in patients with unexplained raised liver transaminases testing for HCV-RNA may be warranted in order to rule out occult or acute HCVinfection.

Before starting anti-HCV therapy determination of HCV genotype and HCV viral load is necessary to estimate the odds for SVR and to determine the rough grids for treatment duration. Current therapy is particularly recommended in patients with a high likelihood of achieving sustained virological response (SVR), i.e. genotypes 2 or 3 and patients infected with genotype 1 if the viral load is $<400000 \mathrm{IU} / \mathrm{ml}$ (Table 1). Recently, first data suggested that the level of HCV-RNA may also influence the natural course of HCV infection in HIV-infected individuals [43]. In this analysis of the EuroSIDA cohort high HCV viral load above $800000 \mathrm{IU} / \mathrm{ml}$ was associated with an increased rate of liver related death. As this is in contrast with all data from HCV-monoinfection it should, however, be discussed with caution.

Liver fibrosis staging may help to guide therapeutic decisions in co-infected patients. However, a liver biopsy is not mandatory for considering treatment of chronic HCV. In case of liver biopsy or FibroScan demonstrating lower stages of liver fibrosis ( $\mathrm{F} 0-1)$, regardless of HCV genotype, treatment can be deferred. In these cases, fibrosis assessment should be carried out at frequent intervals to monitor for fibrosis progression. Serum markers for liver fibrosis such as
APRI, FIB-4, Fibrotest and others have been validated in HIV/HCV co-infected patients and may help to assess and monitor the extent of liver fibrosis. A liver disease stage assessment is especially important to perform in patients with a low chance of SVR. Patients who are diagnosed with liver cirrhosis must also be evaluated for oesophageal varices and hepatocellular carcinoma and monitored accordingly thereafter.

More recently, insulin resistance, which can be determined using the homeostasis model assessment of insulin resistance [44], has been repeatedly reported as a negative predictor of achievement of SVR [45, 46] and may therefore also be considered during pretreatment evaluation. Though currently there is no data suggesting that treatment of insulin resistance prior to start of pegylated interferon and ribavirin therapy actually translates into higher rates of SVR, experts recommend to effectively manage insuline resistance before treating HCV infection if possible [29].

Determination of antinuclear (ANA) and liver kidney microsome (LKM) autoantibodies can help to identify underlying autoimmune hepatitis [47], a disease which may significantly worsen under interferon therapy. Therefore patients with a homogenous pattern of ANA or positive anti-LKM should be further evaluated for autoimmune hepatitis, especially in the presence of ALT elevation during treatment. Similarly screening for thyroid autoantibodies will help to identify individuals at particular risk for the development 
of autoimmune thyroiditis [48-50]. Controlling thyroid stimulating hormone (TSH) at baseline and every 12 weeks under therapy helps to identify patients with thyroid dysfunction under interferon therapy and allows early therapeutic intervention.

During interferon and ribavirin therapy, the most common adverse events observed are flu-like symptoms, anemia, leucopenia and mood disorders. Flu-like symptoms may be severe and can require concomitant therapy with non-steroidal anti-inflammatory drugs (NSAID). Starting NSAID a few hours before the weekly injection of pegylated interferon and continue for another $24-48$ hours after the injection may help to stop or relief symptoms in severely affected individuals. The maximum hemoglobin loss is usually observed within the first 12 weeks of interferon and ribavirin therapy and frequent monitoring at 1 - 2 week intervals is advised during this time in order to timely adjust ribavirin doses accordingly (Table 1). Particular attention must be given to patients with reduced creatinine clearance who have a higher risk for ribavirin associated anemia. In case of creatinine clearance $<50$ $\mathrm{ml} / \mathrm{min}$ ribavirin therapy should only be started with reduced doses and after consultation with an experienced hepatologist and/or nephrologist. Determination of week 2 hemoglobin concentrations may help to estimate the full extent of ribavirin induced anemia and allow dose modifications in patients at risk earlier [51]. Patients with preexisting coronary heart disease are more vulnerable to ribavirin associated anemia and subsequently lower thresholds of hemoglobin decay must be taken into account when assessing the need for ribavirin dose reductions. In patients with persisting anemia despite ribavirin dose reductions interferon induced auto-immune anemia should be a differential diagnosis. Observed leucopenia and thrombocytopenia are mainly due to the interferon associated bone marrow suppression and may require dose adaptations according to the summary of product characteristics of the interferon used.

Mood disorders are frequently encountered in HCV-positive patients undergoing interferon based therapies. Patients with preexistent psychiatric comorbidities should be evaluated prior and ideally monitored during interferon therapy by a psychiatrist. In case mood disorders such as depression occur during the treatment course, pharmacologic interventions have shown to be of great success and few patients have to stop interferon therapy due to psychiatric adverse events [52].

\section{Therapy of Hepatitis C INFECTION}

Current treatment of choice is pegylated interferon in combination with ribavirin. The standard dose for pegylated interferon alfa-2a is $180 \mu \mathrm{g}$ once weekly, and for pegylated interferon alfa-2b it is $1.5 \mu \mathrm{g} / \mathrm{kg}$ bodyweight once weekly. In contrast to $\mathrm{HCV}$ monoinfected patients in $\mathrm{HIV} / \mathrm{HCV}$ coinfected patients a bodyweight-adapted dosage of ribavirin is recommended for all HCV genotypes because historical comparison demonstrated superiority of a weight-adapted dosage also in patients with genotype 2 or 3 infections [53]. Patients with a bodyweight $<75 \mathrm{~kg}$ should receive $1000 \mathrm{mg}$ ribavirin, patients $\geq 75 \mathrm{~kg} 1200 \mathrm{mg}$ per day.

The duration of treatment should be individualized according to HCV genotype, baseline HCV viral load, and response to treatment (Figure 1, [29]). Based on the data from the PRESCO trial patients with genotype 1 and 4 infections should be treated for 48 weeks in case of a rapid HCV-RNA clearance below the level of detection at week 4 (rapid virological response). In all other cases treatment should be prolonged to 72 weeks [54]. On the other side, in patients with a rapid virological response, i.e. a negative $\mathrm{HCV}-\mathrm{RNA}$ at week 4 and a genotype 2 or 3 infection, the overall treatment course may be reduced to 24 weeks. However, this should be only done in patients with a low baseline HCV viral load < 400000 I.U./ml and only minimal liver fibrosis [55]. All other patients with a genotype 2 or 3 infection should be treated for 48 weeks. Treatment may be stopped if insufficient virological response is observed. Thus, if the decay of HCVRNA is less than $2 \log 10$ at week 12 or HCV-RNA is still positive at week 24 treatment should be stopped. Under these treatment modalities, the response rates in $\mathrm{HIV} / \mathrm{HCV}$ coinfected patients have significantly improved over the years, closing the gaps between $\mathrm{HCV}$ monoinfected and $\mathrm{HIV} / \mathrm{HCV}$ coinfected patients (Table 2). Currently in $\mathrm{HIV} / \mathrm{HCV}$ coinfected

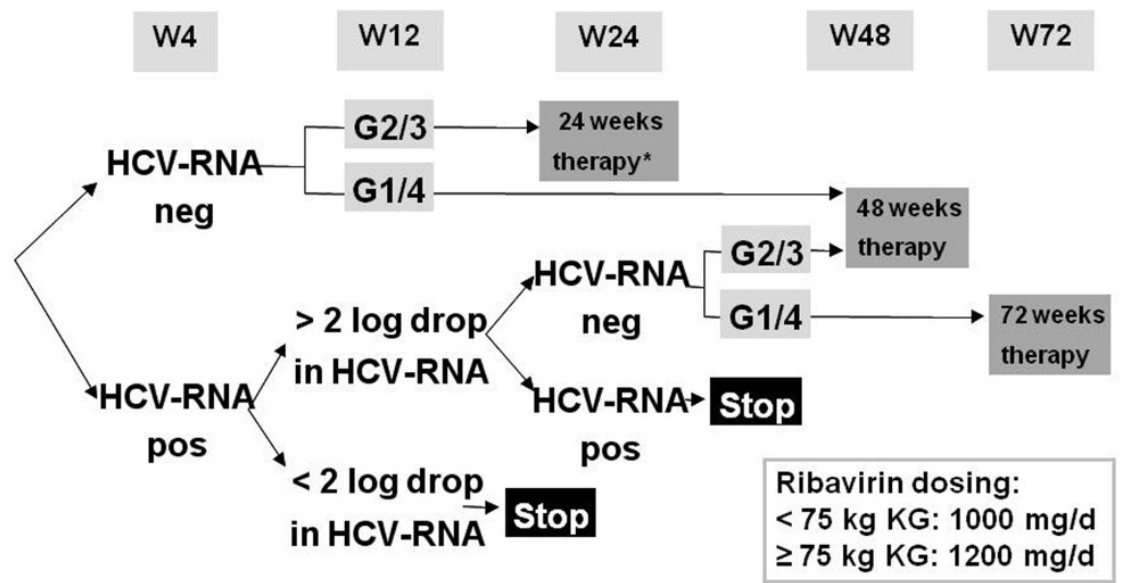

"patients with low baseline viral load ( $\mathrm{HCV}-\mathrm{RNA}<400.000 \mathrm{IU} / \mathrm{ml}$ ) and minimal fibrosis (F0 - F1)
Fig. 1. Guidelines of the European AIDS Society (EACS) for the treatment of chronic hepatitis $\mathrm{C}$ infection in $\mathrm{HIV} / \mathrm{HCV}$ coinfected individuals.

$\mathrm{W}=$ week, neg $=$ negative, pos $=$ positive, $\mathrm{G}=\mathrm{HCV}$-genotype 
Table 2. Studies on the treatment of chronic HCV infection in HIV/HCV co-infected patients.

\begin{tabular}{|c|c|c|c|c|c|c|c|c|c|c|}
\hline \multirow[t]{2}{*}{ Study } & \multirow{2}{*}{$\begin{array}{l}\text { Number } \\
\text { patients } \dagger\end{array}$} & \multirow[t]{2}{*}{ Study type } & \multicolumn{2}{|c|}{ PegIFN Therapy } & \multicolumn{3}{|c|}{ Patient characteristics } & \multicolumn{3}{|c|}{ SVR rates } \\
\hline & & & Duration & $\begin{array}{l}\text { RBV dosing } \\
\mathrm{mg} / \text { day }\end{array}$ & $\underset{\%}{\operatorname{High} \text { VL }}$ & $\begin{array}{c}\text { GT1 } \\
\%\end{array}$ & $\underset{\%}{\text { IDU }}$ & $\begin{array}{c}\text { Overall } \\
\%\end{array}$ & $\underset{\%}{\text { GT } 1 / 4}$ & $\underset{\%}{\text { GT } 2 / 3}$ \\
\hline $\begin{array}{l}\text { Laguno et al. } 2004 \\
\text { [61] }\end{array}$ & 52 & $\begin{array}{l}\text { prospective randomized } \\
\text { controlled clinical trial }\end{array}$ & $24-48$ & $800-1200$ & $47 *$ & 49 & 82 & 44 & 38 & 53 \\
\hline $\begin{array}{l}\text { Nunez et al. } 2007 \\
\text { [62] }\end{array}$ & 389 & prospective clinical trial & $24-72$ & $1000-1200$ & $67^{*}$ & 49 & 90 & 50 & 35 & 72 \\
\hline $\begin{array}{l}\text { Laguno et al. } 2009 \\
\text { [63] }\end{array}$ & 182 & $\begin{array}{l}\text { prospective randomized } \\
\text { controlled clinical trial }\end{array}$ & 48 & $800-1200$ & $59^{*}$ & 45 & 76 & 44 & 30 & 66 \\
\hline $\begin{array}{l}\text { Torriani et al. } 2004 \\
\text { [64] }\end{array}$ & 289 & $\begin{array}{l}\text { prospective randomized } \\
\text { controlled clinical trial }\end{array}$ & 48 & 800 & $72 *$ & 61 & 62 & 40 & $29 \ddagger$ & 62 \\
\hline $\begin{array}{l}\text { Mira et al. } 2009 \\
\text { [65] }\end{array}$ & 542 & observational cohort study & $24-48$ & $600-1500$ & $58^{*}$ & 54 & 85 & 38 & 25 & 63 \\
\hline $\begin{array}{l}\text { Rodriguez-Torres } \\
\text { et al. } 2009 \text { [66] }\end{array}$ & 410 & $\begin{array}{l}\text { prospective randomized } \\
\text { controlled clinical trial }\end{array}$ & 48 & $800-1200$ & $80^{*}$ & 100 & n.r. & - & 21 & - \\
\hline $\begin{array}{l}\text { Voigt et al. } 2005 \\
\text { [67] }\end{array}$ & 122 & prospective clinical trial & $24-48$ & 800 & $45^{*}$ & 56 & 61 & 25 & 18 & 44 \\
\hline $\begin{array}{l}\text { Berenguer et al. } \\
2009 \text { [68] }\end{array}$ & 557 & observational cohort study & $\#$ & $\#$ & $61 *$ & 51 & 80 & 32 & 17 & 45 \\
\hline $\begin{array}{l}\text { Carrat et al. } 2004 \\
\text { [69] }\end{array}$ & 205 & $\begin{array}{l}\text { prospective randomized } \\
\text { controlled clinical trial }\end{array}$ & 48 & 800 & $63^{*}$ & 48 & 80 & 27 & 17 & $44 \$$ \\
\hline $\begin{array}{l}\text { Chung et al. } 2004 \\
\text { [70] }\end{array}$ & 66 & $\begin{array}{l}\text { prospective randomized } \\
\text { controlled clinical trial }\end{array}$ & 48 & $600-1000 \S$ & $83 *$ & 77 & not rep. & 27 & $14 \ddagger$ & $73 \$$ \\
\hline
\end{tabular}

† number of patients who received pegylated interferon;

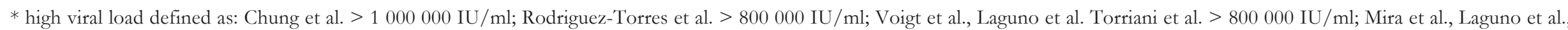
Nunez et al. HCV-RNA > $600000 \mathrm{IU} / \mathrm{ml}$; Berenguer et al., Carrat et al. > $500000 \mathrm{IU} / \mathrm{ml}$;

$\ddagger$ only reported for GT1 infections;

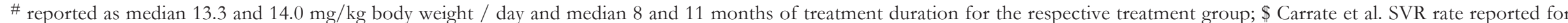
GT 2,3 or 5 infections: Chung et al. SVR rate reported for non-1 genotypes;

$\mathbb{S}$ dose escalating regimen, starting at $600 \mathrm{mg}$; n.r. rot reported in the abstract 
patients a sustained virological response, i.e. a negative HCV-RNA 24 weeks after stop of treatment, is observed in genotype 1 or 4 infections in about $35 \%$ and in genotype 2 and 3 infections in about $70 \%$ of patients [56].

In patients with acute $\mathrm{HCV}$ infection, $\mathrm{HCV}$ therapy is recommended if $\mathrm{HCV}-\mathrm{RNA}$ is confirmed positive (1 week apart) by week 12 post HCV transmission, as SVR rates following treatment of acute $\mathrm{HCV}$-infection are higher than for treatment of chronic HCV [57]. Most experts recommend therapy for 24 weeks with Peg-INF and ribavirin; however the duration of therapy and use of ribavirin is currently under discussion. HCV-RNA levels at week 4 and 12 may help to guide treatment duration [58].

\section{NON-RESPONDER}

After failure of a modern pegylated interferon therapy with weight based ribavirin dosage according to present guidelines there is at present no reasonable treatment option for $\mathrm{HIV} / \mathrm{HCV}$ coinfected patients. An interferon maintenance therapy in order to delay or stop the progression of liver fibrosis has been discussed in the past as a possible treatment option. However, within the two largest studies on this issue (HALT-C for HCV monoinfected and SLAM-C for $\mathrm{HCV} / \mathrm{HIV}$ coinfected patients $[59,60])$ this treatment option did not result in any benefit for the patients so that no continuation of interferon treatment is useful after treatment failure.

Patients who have been treated in the past with a standard interferon (not pegylated) or without / without sufficient dosage of ribavirin should be individually discussed with an experienced hepatologist / HIV specialist in how far a new treatment with pegylated interferon in combination with ribavirin may be useful and may result in sustained virological response. At present a whole array of new small molecules for the treatment of hepatitis $\mathrm{C}$ is in clinical development. Many of the new drugs - like the most advanced in clinical development telaprevir and boceprevir - are, however, metabolized via the cytochrome P-450 system so that relevant pharmacokinetic interactions with antiretroviral drugs, in particular ritonavir boosted protease inhibitors and non-nucleoside reverse transcriptase inhibitors, are to be expected. In addition most HCV-protease inhibitors do not seem to have marked antiviral efficacy against HCV genotype 3 and 4 and are designed for highest efficacy in the difficult to treat genotype 1 infection. Thus at present it is not foreseeable when these new compounds will be available for $\mathrm{HIV} / \mathrm{HCV}$ coinfected patients in clinical routine.

\section{CONCLUSION}

Due to the enhanced risk for progression of chronic hepatitis C, every $\mathrm{HIV} / \mathrm{HCV}$ coinfected patient should be evaluated for treatment with a pegylated interferon ribavirin combination therapy. The standard of care for the treatment of chronic $\mathrm{HCV}$ infection in $\mathrm{HIV}$-infected remains a pegylated interferon in combination with weight-adapted ribavirin. The duration of therapy is dependent on HCV genotype, baseline $\mathrm{HCV}$ viral load, and treatment response. In the last years, due to the introduction of weight based ribavirin and an overall prolongation of the course of treatment treatment response rates in $\mathrm{HIV} / \mathrm{HCV}$ coinfected patients have been enhanced and are coming closer to response rates observed in HCV monoinfected patients. Currently treatment response rates in patients with genotype 1 and 4 infections and 2 and 3 infections are observed in $35 \%$ and $70 \%$ of patients respectively.

Higher CD4-cell counts are associated with higher treatment response rates. Thus HAART should not be withheld from patients due to concerns of drug related hepatotoxicity and in patients with reduced CD4cell counts HAART should be started first. Under concomitant use of HAART and pegylated interferon and ribavirin combination therapy drug to drug interactions and cumulated toxicity between nucleoside analogues and anti-HCV therapy may be observed and HAART should be adjusted accordingly. Importantly concomitant didanosine use is contraindicated and zidovudine and stavudine should be avoided if possible.

The development of new drugs for the treatment of chronic hepatitis $C$ represents a promising perspective also for HIV positive patients. However, due to necessary pharmacokinetic interaction studies, these substances will probably reach clinical routine for HIV patients later than HCV monoinfected patients. Therefore at present waiting for new substances is not an alternative to a modern pegylated interferon/ribavirin therapy.

\section{REFERENCES}

1. Mocroft A, Brettle R, Kirk O, et al. Changes in the cause of death among HIV positive subjects across Europe: results from the EuroSIDA study. Aids 2002;16(12):166371.

2. Rosenthal E, Pialoux G, Bernard N, et al. Liver-related mortality in human-immunodeficiency-virus-infected patients between 1995 and 2003 in the French GERMIVIC Joint Study Group Network (MORTAVIC 2003 Study). J Viral Hepat 2007 Mar;14(3):183-8.

3. Soriano V, Mocroft A, Rockstroh J, et al. Spontaneous viral clearance, viral load, and genotype distribution of hepatitis $\mathrm{C}$ virus (HCV) in HIV-infected patients with antiHCV antibodies in Europe. J Infect Dis 2008 Nov 1;198(9):1337-44.

4. Martin-Carbonero L, Benhamou Y, Puoti M, et al. Incidence and predictors of severe liver fibrosis in human immunodeficiency virus-infected patients with chronic hepatitis C: a European collaborative study. Clin Infect Dis 2004 Jan 1;38(1):128-33.

5. Sulkowski MS, Mehta SH, Torbenson MS, et al. Rapid fibrosis progression among HIV/hepatitis C virus-co-infected adults. AIDS 2007 Oct 18;21(16):2209-16.

6. Berenguer J, Alvarez-Pellicer J, Martin PM, et al. Sustained virological response to interferon plus ribavirin reduces liver-related complications and mortality in patients coinfected with human immunodeficiency virus and hepatitis C virus. Hepatology 2009 Aug;50(2):407-13.

7. Rauch A, Rickenbach M, Weber R, et al. Unsafe sex and increased incidence of hepatitis $\mathrm{C}$ virus infection among HIV-infected men who have sex with men: the Swiss HIV Cohort Study. Clin Infect Dis 2005 Aug 1;41(3):395402. 
8. Rockstroh JK, Mocroft A, Soriano V, et al. Influence of hepatitis $\mathrm{C}$ virus infection on HIV-1 disease progression and response to highly active antiretroviral therapy. J Infect Dis 2005 Sep 15;192(6):992-1002.

9. World Health Organization. Global prevalence of hepatitis A, B and C. Weekly Epidemiological Record 2002; $77(6): 41-8$.

10. Trevino A, Rivas P, Herrero-Mendoza M, Toro C, Soriano V, de Mendoza C. Newly Diagnosed HIV-1 Individuals in Spain since Year 2000. Non-B Subtypes, and Hepatitis $\mathrm{C}$ and $\mathrm{B}$ Virus Co-infections. 16th Conference on Retroviruses and Opportunistic Infections. Montreal, Canada, 2009:Abstract 300.

11. UNAIDS. Report on the global HIV/AIDS epidemic 2008. Geneva, Switzerland, 2008

12. The future of harm reduction programmes in Russia. Lancet 2009 Oct 10;374(9697):1213.

13. Fierer D, Fishman S, Uriel A, et al. Characterization of an Outbreak of Acute HCV Infection in HIV-infected Men in New York City. 16th Conference on Retroviruses and Opportunistic Infections. Montreal, Canada, 2009:Abstract 802.

14. Gallotta G, et al. Acute hepatitis $C$ virus in HIV co-infected men who have sex with men: Milan, 1996 - 2007. 4th International Workshop on HIV and Hepaitits Co-infection. Madrid, Spain, 2008:Abstract 47.

15. Giraudon I, Ruf M, Maguire H, et al. Increase in diagnosed newly acquired hepatitis C in HIV-positive men who have sex with men across London and Brighton, 2002-2006: is this an outbreak? Sex Transm Infect 2008 Apr;84(2):111-5.

16. Larsen C, Alric L, I A, et al. Acute hepatitis C in HIV-infected men who have sex with men in France in 2006 and 2007. 58th Annual Meeting of the American Association for the study of the liver. Boston, USA, 2007:Abstract 894.

17. Luetkemeyer A, Hare CB, Stansell J, et al. Clinical presentation and course of acute hepatitis $\mathrm{C}$ infection in HIVinfected patients. J Acquir Immune Defic Syndr 2006; 41(1):31-6.

18. Matthews G, Hellard M, Haber P, et al. Characteristics and Treatment Outcomes among HIV-Infected Individuals in the Australian Trial in Acute Hepatitis C. Clin Infect Dis 2009;48:650 - 8.

19. Ruf M, Cohuet S, Maguire H, et al. Setting up an enhanced surveillance of newly acquired hepatitis $\mathrm{C}$ infection in men who have sex with men: a pilot in London and South East region of England. Euro Surveill 2008 Nov 20;13(47).

20. Urbanus AT, van de Laar TJ, Stolte IG, et al. Hepatitis C virus infections among HIV-infected men who have sex with men: an expanding epidemic. Aids 2009 Jun 17.

21. Vogel M, Deterding K, Wiegand J, et al. Initial presentation of acute hepatitis $\mathrm{C}$ virus (HCV) infection among HIV-negative and HIV-positive individuals-experience from 2 large German networks on the study of acute HCV infection. Clin Infect Dis 2009 Jul 15;49(2):317-9; author reply 9 .

22. Gambotti L, Batisse D, Colin-de-Verdiere N, et al. Acute hepatitis $\mathrm{C}$ infection in HIV positive men who have sex with men in Paris, France, 2001-2004. Euro Surveill 2005;10(5):115-7.

23. Marincovich B, Castilla J, del Romero J, et al. Absence of hepatitis $\mathrm{C}$ virus transmission in a prospective cohort of heterosexual serodiscordant couples. Sex Transm Infect 2003;79(2):160-2.

24. Vandelli C, Renzo F, Romano L, et al. Lack of evidence of sexual transmission of hepatitis $\mathrm{C}$ among monogamous couples: results of a 10-year prospective follow-up study. Am J Gastroenterol 2004 May;99(5):855-9.

25. Fisher M, Richardson D, Sabin C. Acute Hepatitis C in
Men Who Have Sex With Men Is Not Confined to Those Infected with HIV, and Their Number Continues to Increase. 14th Conference on Retroviruses and Opportunistic Infections. Boston, USA, 2008:Abstract 130.

26. Brau N, Salvatore M, Rios-Bedoya CF, et al. Slower fibrosis progression in $\mathrm{HIV} / \mathrm{HCV}$-coinfected patients with successful HIV suppression using antiretroviral therapy. J Hepatol 2006 Jan;44(1):47-55.

27. Bani-Sadr F, Lapidus N, Bedossa P, et al. Progression of fibrosis in HIV and hepatitis $C$ virus-coinfected patients treated with interferon plus ribavirin-based therapy: analysis of risk factors. Clin Infect Dis 2008 Mar 1;46(5):768-74

28. Rockstroh J, Ahlenstiel G, Vogel M, et al. The influence of nucleoside free HAART on the treatment of chronic hepatitis $\mathrm{C}$ with pegylated interferon / ribavirin combination treatment. 42nd Annual Meeting of the European Association for the Study of the Liver. Barcelona, Spain, 2007:Abstract 636.

29. Rockstroh J, Benhamou Y, Bhagani S, et al. European AIDS Clinical Society (EACS) Guidelines for the clinical management and treatment of chronic hepatitis $B$ and $C$ co-infection in HIV-infected adults - 2009. Available at: http://www.europeanaidsclinicalsociety.org/guidelines.asp.

30. Opravil M, Sasadeusz J, Cooper DA, et al. Effect of baseline CD4 cell count on the efficacy and safety of peginterferon Alfa-2a (40KD) plus ribavirin in patients with $\mathrm{HIV} /$ hepatitis C virus coinfection. J Acquir Immune Defic Syndr 2008 Jan 1;47(1):36-49.

31. Bani-Sadr F, Carrat F, Pol S, et al. Risk factors for symptomatic mitochondrial toxicity in HIV/hepatitis $\mathrm{C}$ viruscoinfected patients during interferon plus ribavirin-based therapy. J Acquir Immune Defic Syndr 2005 Sep 1;40(1): 47-52.

32. Laguno M, Milinkovic A, de Lazzari E, et al. Incidence and risk factors for mitochondrial toxicity in treated HIV/HCV-coinfected patients. Antivir Ther 2005;10(3): 423-9.

33. Alvarez D, Dieterich DT, Brau N, Moorehead L, Ball L, Sulkowski MS. Zidovudine use but not weight-based ribavirin dosing impacts anaemia during HCV treatment in HIV-infected persons. J Viral Hepat 2006 Oct;13(10): 683-9.

34. Bani-Sadr F, Goderel I, Penalba C, et al. Risk factors for anaemia in human immunodeficiency virus/hepatitis $C$ virus-coinfected patients treated with interferon plus ribavirin. J Viral Hepat 2007 Sep;14(9):639-44.

35. Nunez M, Ocampo A, Aguirrebengoa K, et al. Incidence of anaemia and impact on sustained virological response in $\mathrm{HIV} / \mathrm{HCV}$-coinfected patients treated with pegylated interferon plus ribavirin. J Viral Hepat 2008 May;15(5): 363-9.

36. Bani-Sadr F, Lapidus N, Melchior JC, et al. Severe weight loss in HIV / HCV-coinfected patients treated with interferon plus ribavirin: incidence and risk factors. J Viral Hepat 2008 Apr;15(4):255-60.

37. Bani-Sadr F, Denoeud L, Morand P, et al. Early virologic failure in HIV-coinfected hepatitis $\mathrm{C}$ patients treated with the peginterferon-ribavirin combination: does abacavir play a role? J Acquir Immune Defic Syndr 2007 May 1; 45(1):123-5.

38. Mira JA, Lopez-Cortes LF, Barreiro P, et al. Efficacy of pegylated interferon plus ribavirin treatment in $\mathrm{HIV} /$ hepatitis $C$ virus co-infected patients receiving abacavir plus lamivudine or tenofovir plus either lamivudine or emtricitabine as nucleoside analogue backbone. J Antimicrob Chemother 2008 Dec;62(6):1365-73.

39. Vispo E, Barreiro P, Pineda JA, et al. Low response to pegylated interferon plus ribavirin in HIV-infected patients with chronic hepatitis $\mathrm{C}$ treated with abacavir. Antivir Ther 2008;13(3):429-37. 
40. Laufer N, Laguno M, Perez I, et al. Abacavir does not influence the rate of virological response in HIV-HCVcoinfected patients treated with pegylated interferon and weight-adjusted ribavirin. Antivir Ther 2008;13(7):953-7.

41. Thomson EC, Nastouli E, Main J, et al. Delayed anti$\mathrm{HCV}$ antibody response in HIV-positive men acutely infected with HCV. Aids 2009 Jan 2;23(1):89-93.

42. Ragni MV, Ndimbie OK, Rice EO, Bontempo FA, Nedjar $\mathrm{S}$. The presence of hepatitis $\mathrm{C}$ virus (HCV) antibody in human immunodeficiency virus-positive hemophilic men undergoing HCV "seroreversion". Blood 1993 Aug 1; 82(3):1010-5.

43. Rockstroh J, Peters L, Soriano V, et al. High HCV Is Associated with an Increased Risk for Mortality in $\mathrm{HIV} / \mathrm{HCV}$-co-infected Individuals. 16th Conference on Retroviruses and Opportunistic Infections. Montreal, Canada, 2009:Abstract 101.

44. Wallace TM, Levy JC, Matthews DR. Use and abuse of HOMA modeling. Diabetes Care 2004 Jun;27(6):1487-95.

45. Cacoub P, Carrat F, Bedossa P, et al. Insulin resistance impairs sustained virological response rate to pegylated interferon plus ribavirin in HIV-hepatitis $\mathrm{C}$ virus-coinfected patients: HOMAVIC-ANRS HC02 Study. Antivir Ther 2009;14(6):839-45.

46. Romero-Gomez M, Del Mar Viloria M, Andrade RJ, et al. Insulin resistance impairs sustained response rate to peginterferon plus ribavirin in chronic hepatitis $\mathrm{C}$ patients. Gastroenterology 2005 Mar;128(3):636-41.

47. Krawitt EL. Autoimmune hepatitis. N Engl J Med 2006 Jan 5;354(1):54-66

48. Gisslinger H, Gilly B, Woloszczuk W, et al. Thyroid autoimmunity and hypothyroidism during long-term treatment with recombinant interferon-alpha. Clin Exp Immunol 1992 Dec;90(3):363-7.

49. Kabbaj N, Guedira MM, El Atmani H, et al. Thyroid disorders during interferon alpha therapy in 625 patients with chronic hepatitis C: a prospective cohort study. Ann Endocrinol (Paris) 2006 Sep;67(4):343-7.

50. Watanabe U, Hashimoto E, Hisamitsu T, Obata H, Hayashi N. The risk factor for development of thyroid disease during interferon-alpha therapy for chronic hepatitis C. Am J Gastroenterol 1994 Mar;89(3):399-403.

51. Reau N, Hadziyannis SJ, Messinger D, Fried MW, Jensen DM. Early predictors of anemia in patients with hepatitis C genotype 1 treated with peginterferon alfa-2a (40KD) plus ribavirin. Am J Gastroenterol 2008 Aug;103(8): 1981-8.

52. Laguno M, Blanch J, Murillas J, et al. Depressive symptoms after initiation of interferon therapy in human immunodeficiency virus-infected patients with chronic hepatitis C. Antivir Ther 2004 Dec;9(6):905-9.

53. Ramos B, Nunez M, Rendon A, et al. Critical role of ribavirin for the achievement of early virological response to $\mathrm{HCV}$ therapy in $\mathrm{HCV} / \mathrm{HIV}$-coinfected patients. J Viral Hepat 2007 Jun;14(6):387-91.

54. Martin-Carbonero L, Nunez M, Marino A, et al. Undetectable hepatitis $\mathrm{C}$ virus RNA at week 4 as predictor of sustained virological response in HIV patients with chronic hepatitis C. AIDS 2008 Jan 2;22(1):15-21.

55. Puoti M, Zanini B, de Luca A, test b. Results of a randomized controlled trial on the impact of prolonged combination anti-HCV treatment on relapse rate in HIV/HCV coinfected pateints: the ROMANCE trial. 3rd International Workshop on HIV and Hepatitis coinfection. Paris, France, 2007:Abstract 1.

56. Rockstroh JK, Bhagani S, Benhamou Y, et al. European
AIDS Clinical Society (EACS) guidelines for the clinical management and treatment of chronic hepatitis B and $\mathrm{C}$ coinfection in HIV-infected adults. HIV Med 2008 Feb;9(2):82-8.

57. Vogel M, Rockstroh JK. Treatment of acute hepatitis C in HIV infection. J Antimicrob Chemother 2009 Oct 27.

58. Vogel M, Dominguez S, Bhagani S, et al. Treatment of acute $\mathrm{HCV}$ infection in HIV-positive patients: experience from a multi-centre European cohort. Antiviral Therapy in press.

59. Di Bisceglie A, Shiffman M, Everson G, test b. Prolonged antiviral therapy with peginterferon to prevent complications of advanced liver disease associated with hepatitis C: results of the hepatitis $\mathrm{C}$ Antiviral Long-term Treatment against Cirrhosis (HALT-C) trial. 58th Annual Meeting of the American Association for the Study of Liver Diseases. Boston, MA, USA, 2007:Abstract LB1.

60. Sherman K, Andersen J, Butt A, et al. Sustained Longterm Antiviral Maintenance with Pegylated Interferon in HCV/HIV-co-infected Patients: Early Viral Response and Effect on Fibrosis in Treated and Control Subjects. 15th Conference on Retroviruses and Opportunistic Infections. Boston, MA, USA, 2008:Abstract 59.

61. Laguno M, Murillas J, Blanco JL, et al. Peginterferon alfa$2 \mathrm{~b}$ plus ribavirin compared with interferon alfa- $2 \mathrm{~b}$ plus ribavirin for treatment of $\mathrm{HIV} / \mathrm{HCV}$ co-infected patients. AIDS 2004 Sep 3;18(13):F27-36.

62. Nunez M, Miralles C, Berdun MA, et al. Role of weightbased ribavirin dosing and extended duration of therapy in chronic hepatitis $\mathrm{C}$ in HIV-infected patients: the PRESCO trial. AIDS Res Hum Retroviruses 2007 Aug; 23(8):972-82.

63. Laguno M, Cifuentes C, Murillas J, et al. Randomized trial comparing pegylated interferon alpha- $2 \mathrm{~b}$ versus pegylated interferon alpha-2a, both plus ribavirin, to treat chronic hepatitis $C$ in human immunodeficiency virus patients. Hepatology 2009 Jan;49(1):22-31.

64. Torriani FJ, Rodriguez-Torres M, Rockstroh JK, et al. Peginterferon Alfa-2a plus ribavirin for chronic hepatitis $\mathrm{C}$ virus infection in HIV-infected patients. N Engl J Med 2004 Jul 29;351(5):438-50.

65. Mira JA, Gutierrez-Valencia A, Gil Ide L, et al. Efficacy and safety of pegylated interferon plus ribavirin in HIV and hepatitis $C$ virus-coinfected patients with advanced immunosuppression. Clin Infect Dis 2009 Oct 15;49(8): e84-91.

66. Rodriguez-Torres M, Slim J, Bhatti L, et al. Standard versus high dose ribavirin in combination with peginterferon alfa-2a (40KD) in genotype 1 (G1) HCV patients coinfected with HIV: Final results of the PARADIGM study. 60th Annual Meeting of the American Association for the Study of the Liver. Boston, USA, 2009:Abstract 1561.

67. Voigt E, Schulz C, Klausen G, et al. Pegylated interferon alpha-2b plus ribavirin for the treatment of chronic hepatitis C in HIV-coinfected patients. J Infect 2006 Jul;53(1):36-42.

68. Berenguer J, Gonzalez-Garcia J, Lopez-Aldeguer J, et al. Pegylated interferon $\{$ alpha\} 2 a plus ribavirin versus pegylated interferon $\{$ alpha $\} 2 \mathrm{~b}$ plus ribavirin for the treatment of chronic hepatitis C in HIV-infected patients. J Antimicrob Chemother 2009 Jun;63(6):1256-63.

69. Carrat F, Bani-Sadr F, Pol S, et al. Pegylated interferon alfa-2b vs standard interferon alfa-2b, plus ribavirin, for chronic hepatitis C in HIV-infected patients: a randomized controlled trial. JAMA 2004 Dec 15;292(23):283948 
70. Chung RT, Andersen J, Volberding P, et al. Peginterferon Alfa-2a plus ribavirin versus interferon alfa-2a plus ribavirin for chronic hepatitis $\mathrm{C}$ in $\mathrm{HIV}$-coinfected persons. N Engl J Med 2004 Jul 29;351(5):451-9.
Address for correspondence:

Prof. Dr. med. Jürgen Rockstroh

Immunologische Ambulanz

Medizinische Klinik und Poliklinik I

Sigmund-Freud-Str. 25

53105 Bonn, Germany

Tel.: $\quad+49-228-28716558$

Fax: +49-228-287 15034

E-mail: juergen.rockstroh@ukb.uni-bonn.de 